\title{
Water footprint mitigation strategies for agrifood products: The application of system dynamics in green marketing
}

\author{
EIRINI AIVAZIDOU ${ }^{1, \mathrm{a}}$, NAOUM TSOLAKIS ${ }^{2}$, DIMITRIOS VLACHOS ${ }^{3}$, \\ ELEFTHERIOS IAKOVOU ${ }^{4}$
}

1,2,3Department of Mechanical Engineering, Aristotle University of Thessaloniki, Greece

4Department of Engineering Technology and Industrial Distribution, Texas A\&M University, USA

a)Corresponding author: aveirini@auth.gr

\begin{abstract}
Water scarcity (WS), which leads to multiple environmental, social and economic ramifications, has emerged as an indisputable concern for both public and private stakeholders. In this context, the water footprint (WF) concept has been introduced for assessing freshwater consumption and pollution at national, corporate or product levels. In the agrifood industry, freshwater is a pivotal constituent since agricultural activities consume 70\% of the global freshwater resources, while food processing operations account for significant freshwater utilization. To that effect, environmentally aware consumers are sensitive to the total product WF generated during agrifood supply chain (SC) operations, as well as to the manner in which the related freshwater exploitation impacts regional WS. Consequently, an increasing number of companies are implementing WF management policies across their agrifood SCs for mitigating freshwater utilization and promoting water-friendly commodities in order to enhance green corporate image and business financial performance. This study proposes a policy-making System Dynamics (SD) model for monitoring both the WF of agrifood products and the profitability of the related SCs in terms of net present value (NPV). The model investigates the effect of various market behaviours in the relation between green image factor (GIF) and regional WS, when WF management strategies are implemented. The SD simulation results reveal that WF mitigation policies have a considerable impact on GIF in environmentally sensitive markets, thus increasing the relevant market share and the agrifood SC stakeholders' profitability. Finally, the research provides managerial insights concerning green marketing interventions in the agrifood sector.
\end{abstract}

Keywords: Agrifood Products, Green Marketing, System Dynamics, Water Footprint.

\section{Introduction}

In recent years, climate change along with increased environmental awareness has shifted consumers' purchasing decisions towards environmentally friendly or else "green" products (Elham R. and Nabsiah A.W. 2011; Rex E. and Baumann H. 2007). Indicatively, sales in the European organic food market grew by approximately $70 \%$ during the period 2004-2012, reaching €24.3 billion (FiBL and IFOAM 2015; Soil Association 2014). However, prevailing marketing practices have failed to educate consumers on sustainability issues and establish a resilient market for eco-friendly products thus far (Peano C. et al. 2015). Therefore, green marketing emerges as a critical factor towards promoting sales and sustaining a 
competitive corporate image compared to traditional marketing (Ko E. et al. 2013). To that end, companies have started to employ green marketing practices, such as eco-certification and eco-branding, in order to trigger consumers' interest in products with sustainable attributes, as well as to foster the profitability of all supply chain (SC) stakeholders (Chkanikova O. and Lehner M. 2014).

The concept of sustainable development has emerged as a key issue in the design and planning of food production systems throughout the entire spectrum of operations, spanning from farming to final household consumption (Tsolakis N.K. et al. 2014). The prominent role of sustainability in the agrifood industry derives from the fact that around one third of the global food supplies is wasted annually. This statistic implies that $24 \%$ of freshwater resources, $23 \%$ of agricultural land, $23 \%$ of fertilizers and a significant amount of energy used during the production, processing, storage and transportation of food are wasted (Kummu M. et al. 2012).

Since the agricultural sector consumes and pollutes approximately $70 \%$ of the global freshwater resources (UNESCO 2009), hence intensifying global water scarcity (WS), environmental concerns focus on the overexploitation of freshwater resources in the agrifood sector (Aivazidou E. et al. 2015). As a consequence, the concept of water footprint (WF) has been introduced for assessing the total direct and indirect freshwater utilization during the production of a commodity or a service (Hoekstra A.Y. 2008). At the same time, WF labelling on food products could assist companies communicate with green consumers and influence their purchasing decisions, thus gaining the market competitive advantage and achieving sustainable financial performance (Sharma A. and Iyer G.R. 2012).

In this context, the aim of the study is to investigate the impact of consumers' environmental awareness in corporate sustainability in terms of freshwater resources' preservation and profitability enhancement. In this paper, we adopt the System Dynamics (SD) methodology in order to monitor the WF and the financial performance of the agrifood SC during different scenarios of consumer behaviours and policy interventions. In fact, SD is a simulation-based tool for analysing the dynamic behaviour of complex systems that has been proven to be useful in strategic policy-making (Roberts E.B. 1978; Sterman J. 2000).

The remainder of the paper is organized as follows. In Section 2, we develop a SD model for investigating the impact of various market behaviours in corporate green image factor (GIF) as a function of regional WS, in case WF management strategies are employed. In Section 3, we elaborate on the results of the agrifood system's WF and net present value (NPV). Finally, Section 4 concludes with managerial insights and directions for future research with respect to green marketing strategies for the sustainable growth of the agrifood sector.

\section{Model Development}

We consider the SC of an agrifood product. The business environment is assumed to be monopolistic, which implies that all stakeholders (suppliers, single manufacturer and consumers) are located within a particular region with specific 
freshwater resources' availability. The agrifood SC under study includes three echelons: (i) the farming stage, where the agricultural commodity is produced, (ii) the food processing stage, during which the raw product is transformed into a marketable food commodity, and (iii) the retailing stage, where demand is defined by the consumers' environmental sensitivity concerning regional WS.

As illustrated in Fig 1, environmental sensitivity is modelled through the GIF concept, which represents a percentage change in consumers' demand (Georgiadis P. and Vlachos D. 2004). Three different market behaviour scenarios are developed as follows. In the base scenario, consumers are not environmentally aware with regard to WF, resulting in zero GIF. In the linear and S-curve scenarios, GIF is expressed as linear and logistic functions of regional WS respectively. In particular, WS is calculated as the ratio of WF to freshwater availability in a specific region (Hoekstra et al. 2012). In case WS is less than one, consumers' demand increases due to positive GIF values and vice versa.

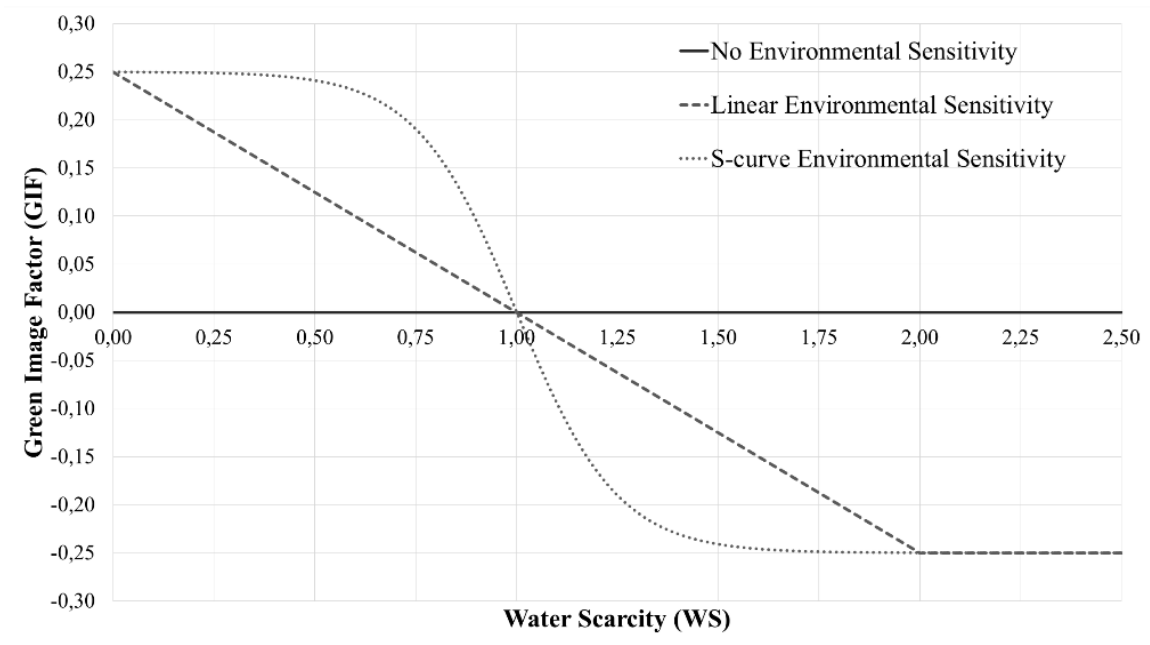

Fig 1. Environmental behaviour scenarios.

Concerning the agrifood system's WF, a significant amount of freshwater resources is consumed and polluted during the farming and food manufacturing stages, thus intensifying regional WS. Considering the prospective water-related policy schemes (European Commission 2012), SC stakeholders aim at implementing effective WF mitigation policies in order to limit regional WS and promote sales of eco-friendly products. The causal loop diagram that illustrates one reinforcing and two balancing feedback loops of the aforementioned conceptual system is depicted in Fig 2.

At the same time, the system's profitability is defined as the margin that is available to stakeholders when costs are deduced from revenues. The cost factors which are identified within the system include the productions costs and the water 
charges. In case a water-related mitigation policy is implemented, the cost of investment is also considered.

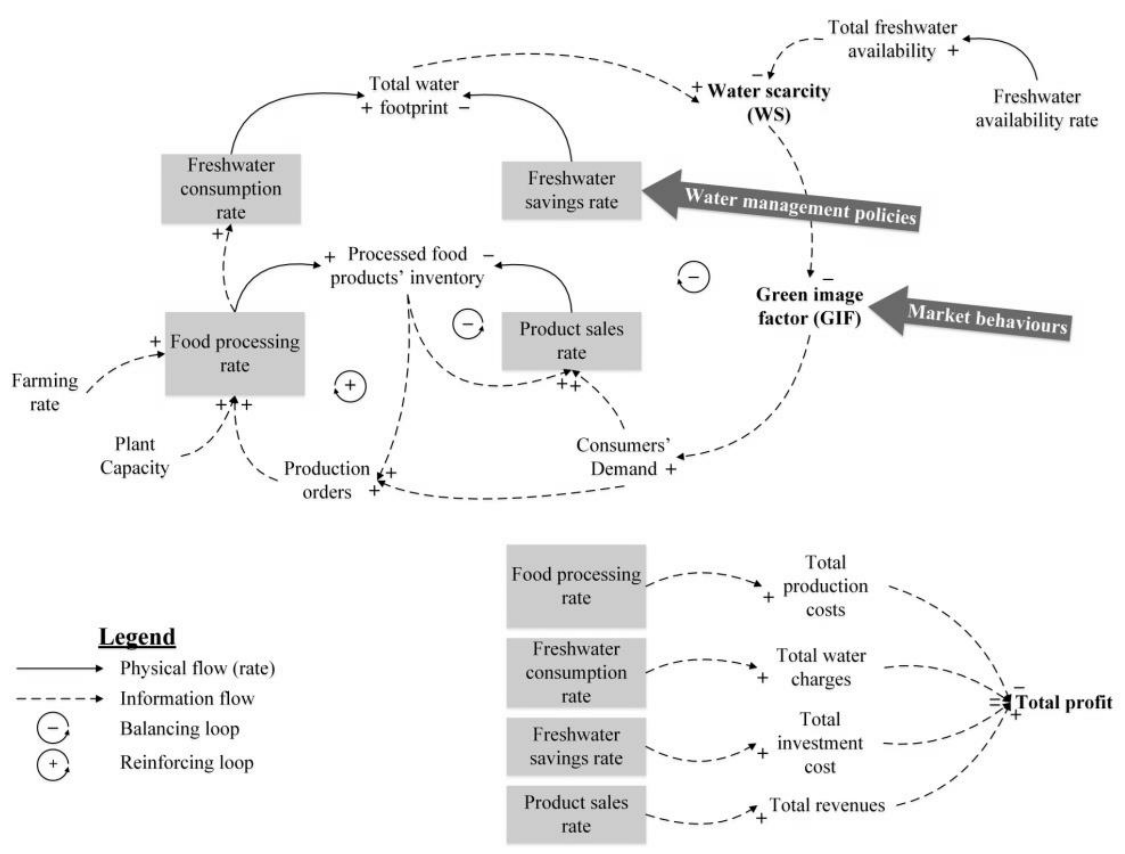

Fig 2. Causal loop diagram.

\section{Results and Discussion}

The applicability of the proposed SD model is demonstrated through the case of wine production. To that end, realistic quantitative estimates associated with freshwater consumption across the wine SC are adopted from literature (Herath et al. 2013). The SD model is simulated with Powersim software. A strategic horizon of 30 years is selected in order to capture the market dynamics with regard to consumers' environmental sensitivity, while the time step is set to 1 year. Moreover, the SD model's validity is verified through indirect structure tests, including extreme condition tests, behaviour sensitivity tests and variable units' consistency.

Thereafter, we estimate the total WF and the NPV of the annual profits, including investment costs in case of WF mitigation policies employment, during the 30year strategic horizon. Table 1 summarizes the observed percentile changes in the WF and the NPV for the different market behaviour scenarios and for each of the two policy options under consideration. The base scenario, where no policy intervention is performed, is used as a benchmark for the calculations. 
Table 1. WF and NPV results (\% change)

\begin{tabular}{llll}
\hline $\mathbf{W F} /$ NPV & Base scenario & Linear scenario & S-curve scenario \\
\hline No policy & $-/-$ & $-11,42 \% /-8,54 \%$ & $-19,75 \% /-19,78 \%$ \\
Policy & $-92,29 \% /-0,20 \%$ & $-90,17 \% /+10,10 \%$ & $-89,70 \% /+17,22 \%$ \\
\hline
\end{tabular}

The simulation results indicate that the implementation of freshwater mitigation practices in environmentally sensitive markets could: (i) significantly reduce the total WF, and (ii) increase the NPV of the overall profits due to the consumer sales growth. In case of no policy intervention, although the total WF and the NPV are reduced in both the linear and S-curve scenarios, the latter case exhibits a higher decrease since environmental sensitivity to WS is more intense. These reductions stem from the decline in sales due to the lower consumers' demand.

On the contrary, if a WF management strategy is applied, a considerable reduction in the total WF in all three scenarios is observed. As regards profitability, the NPV is slightly decreased due to high investment costs in the base scenario, where there is a lack of environmental sensitivity. Nevertheless, in the linear and S-curve scenarios, the reduced freshwater consumption leads to low regional WS, thus increasing the GIF which in turn boosts consumer sales and increases the NPV.

\section{Conclusions}

In this manuscript, we propose a SD model for monitoring the WF of agrifood products and the profitability of the related SCs. Specifically, our modelling approach investigates the manner in which various market behaviours affect corporate GIF according to regional WS, in case WF mitigation strategies are implemented. The numerical example documents that freshwater management policies in environmentally sensitive markets could promote eco-friendly agrifood products and increase market share, thus enhancing business financial performance.

As regards future research, focus should be placed on the stimulating role of green marketing techniques upon consumers' environmental sensitivity. In order to exploit the proposed SD simulation tool, it is suggested that marketing specialists should further study the application of WF labelling and branding in agrifood commodities for guiding consumers towards green purchasing decisions.

\section{Acknowledgments}

This research has received funding from the European Union's Seventh Framework Programme (FP7-REGPOT-2012-2013-1) under Grant Agreement No. 316167 (Project Acronym: GREEN-AgriChains). In addition, E. Aivazidou is grateful to the Public Benefit Foundation Alexander S. Onassis for awarding her a fellowship to conduct this research work as a part of her doctoral studies. 


\section{References}

Aivazidou E., Tsolakis N., Vlachos D., Iakovou, E. (2015). Water Footprint Management Policies for Agrifood Supply Chains: A Critical Taxonomy and a System Dynamics Modelling Approach. Chemical Engineering Transactions, 43, pp. 115-120.

Chkanikova O., Lehner M. (2014). Private eco-brands and green market development: towards new forms of sustainability governance in the food retailing. Journal of Cleaner Production, Article in Press.

Elham R., Nabsiah A.W. (2011). Investigation of green marketing tools' effect on consumers' purchase behavior. Business Strategy Series, 12(2), pp. 73-83.

European Commission (2012). Report from the Commission to the European Parliament and the Council on the Implementation of the Water Framework Directive (2000/60/EC) - River Basin Management Plans. Brussels, Belgium: European Commission.

FiBL, IFOAM (2015). The world of organic agriculture - Statistics \& emerging trends 2015. Frick, Switzerland: Research Institute of Organic Agriculture, Bonn, Germany: International Federation of Organic Agriculture.

Georgiadis P., Vlachos D. (2004). The effect of environmental parameters on product recovery. European Journal of Operational Research, 157, pp. 449-464.

Herath I., Green S., Singh R., Horne D., van der Zijpp S., Clothier, B. (2013). Water footprinting of agricultural products: a hydrological assessment for the water footprint of New Zealand's wines. Journal of Cleaner Production, 41, pp. 232-243.

Hoekstra A.Y. (2008). Water neutral: Reducing and offsetting the impacts of water footprints - Value of Water Research Report Series No. 28. Delft, The Netherlands: UNESCO-IHE.

Hoekstra A.Y., Mekonnen M.M., Chapagain A.K., Mathews R.E., Richter B.D. (2012). Global Monthly Water Scarcity: Blue Water Footprints versus Blue Water Availability. PLoS ONE, 7(2), e32688.

Ko E., Hwang Y.K., Kim E.Y. (2013). Green marketing functions in building corporate image in the retail setting. Journal of Business Research, 66(10), pp. 1709-1715.

Kummu M., de Moel H., Porkka M., Siebert S., Varis O., Ward P.J. (2012). Lost food, wasted resources: Global food supply chain losses and their impacts on freshwater, cropland, and fertiliser use. Science of the Total Environment, 438, pp. 477-489.

Peano C., Baudino C., Tecco N., Girgenti V. (2015). Green marketing tools for fruit growers associated groups: application of the Life Cycle Assessment (LCA) for strawberries and berry fruits ecobranding in northern Italy. Journal of Cleaner Production, 104, pp. 59-67.

Rex E., Baumann H. (2007). Beyond ecolabels: what green marketing can learn from conventional marketing. Journal of Cleaner Production, 15, pp. 567-576.

Roberts E.B. (1978). Managerial Applications of System Dynamics. Cambridge, USA: Pegasus Communications Inc.

Sharma A., Iyer G.R. (2012). Resource-constrained product development: Implications for green marketing and green supply chains. Industrial Marketing Management, 41(4), pp. 599-608.

Soil Association (2014). Organic market report 2014. Bristol, UK: Soil Association.

Sterman J. (2000). Business Dynamics: Systems Thinking and Modelling for a Complex World. Boston, USA: McGraw-Hill Higher Education.

Tsolakis N.K., Keramydas C.A., Toka A.K., Aidonis D.A., Iakovou E.T. (2014). Agrifood supply chain management: A comprehensive hierarchical decision-making framework and a critical taxonomy. Biosystems Engineering, 120, pp. 47-64.

UNESCO (2009). The United Nations world water development Report 3 - Water in a changing world. Paris, France: UNESCO, London, UK: Earthscan Publications Ltd. 